\title{
Nipah Virus Infection, a High Priority Disease: History, Facts, Transmission, Symptoms, Prevention and Treatment
}

\author{
Vinil Upendrababu \\ Faculty of Nursing, College of Health Sciences, Wollega University, Nekemte, Ethiopia \\ Email address: \\ vinilupendrababu@gmail.com

\section{To cite this article:} \\ Vinil Upendrababu. Nipah Virus Infection, a High Priority Disease: History, Facts, Transmission, Symptoms, Prevention and Treatment. \\ International Journal of Biomedical Science and Engineering. Vol. 6, No. 2, 2018, pp. 38-42. doi: 10.11648/j.ijbse.20180602.13
}

Received: May 27, 2018; Accepted: June 25, 2018; Published: July 21, 2018

\begin{abstract}
NiV is a zoonotic virus; the virus often infects mammals such as pigs and fruit bats (Pteropodidae), but they may be asymptomatic. Nipah virus infection transferred by contact with an NiV-infected animal or person or their secretions that has a high fatality rate in infected humans. The patient commonly present with the symptoms that vary from none to fever, cough, headache, dyspnea and confusion and at the end patient condition may worsen into a coma over a day or two. Though there is no significant medications or vaccination against this fatal disease, knowledge about the preventive measures of transmission of disease is inevitable to prevent the occurrence of $\mathrm{NiV}$ infection.
\end{abstract}

Keywords: Nipah Virus Infection, A High Priority Disease, History, Facts, Transmission, Symptoms, Prevention and Treatment

\section{Introduction}

Nipah, an RNA virus, is an emerging zoonotic virus can cause a range of mild to severe disease both in human beings and other mammals. Nipah virus is named after Sungai Nipah Village in Perak, Malaysia where the virus was discovered. Nipah virus is closely related to Hendra virus [2]. Both are members of the genus Henipavirus, a new class of virus in the Paramyxoviridae family. Although Nipah virus infection is a high priority disease on the WHO reaearch and development blue print, there is no specific treatment or vaccination for this fatal illness. The primary treatment for humans is supportive care.

Even though Nipah virus has caused only a few outbreaks, it infects a wide range of animals and causes severe disease and death in people, making it a major public health concern [3]. Since its discovery there have been yearly outbreaks and the mortality rate of confirmed cases has been almost 70 $100 \%$ in most of places where outbreaks has been reported.

\section{History of Nipah Viral Infection}

Nipah Virus first recognized in 1999 during an outbreak among pig farmers in the Malaysian village of kampung Sungai Nipah. On this occasion, pigs were the intermediate hosts. Although Nipah virus encephalitis outbreak was first reported in September 1998, it was firstly documented in 1999 [4]. Subsequently, other outbreaks were reported in some other Malaysian states by February 1999 and it had been spread to Singapore by March 1999. Both of these places main victims were pig farmers or abattoir workers who handled pigs. As a result of this outbreak, over 1 million pigs were culled in Malaysia. More than 200 victims were suffered from this infection during this severe outbreak. Most of the victims in Malaysia and Singapore were shown severe febrile encephalitis with a case fatality rate of $38 \%[5]$. Autopsy report of diseases ones note diffuse vasculitis most prominently involving the central nervous system with intense immune staining of endothelial cells with anti-Nipah virus hyperimmune serum.

In the 10 years following the Nipah outbreak in Malaysia, no further human cases of Nipah viral infection had been reported from Malaysia, but 8 human outbreaks of $\mathrm{NiV}$ infection had been reported in Bangladesh from 2001 through 2008, all occurred between December and May. A total of 135 human cases of Nipah infection in Bangladesh were recognized; among that 98 victims (73\%) died [6]. In Bangladesh (2001) humans were infected with Nipah virus after consuming date palm sap that had been contaminated by infected fruit bats (Pteropodidae bat species), Since then, 
nearly annual outbreaks have occurred in that country.

Periodically, NiV infection also found in eastern India as per WHO. India reported two outbreaks of Nipah virus encephalitis in the eastern state of West Bengal, bordering Bangladesh, in 2001 and 2007. One outbreak of NiV occurred in Siliguri, India, 15 kilometers north of the Bangladesh border in January and February 2001 and a second NiV outbreak was reported by newspapers in Nadia District, India also close to the border with Bangladesh, in 2007. Around 71 cases with 50 deaths ( $70 \%$ of the cases) were reported in two outbreaks [7]. Recently, again the Nipah virus has claimed around 15 lives in the Kerala, southernmost state of India, over the past two weeks.

From 1998 to 2015, more than 600 cases of Nipah virus humen infections were reported. More recent outbreaks in Bangladesh and India are linked with respiratory disease and manifest an even higher case fatality rate, that occasionally reaches a staggering $100 \%$ [8]. Because of the widespread dispersion of the bat species Pteropodidae across the globe, Nipah outbreak has been observed in countries including Australia, Bangladesh, India, Philippines, Indonesia, Veitnam, Cambodia, China, Thailand, Iran, Madagascar and most of the Africa

\section{Structure of Nipah Virus}

Nipah virus is a highly pathogenic paramyxovirus causing deadly encephalitis in humans.

Single stranded negative sense RNA, 18246 bp (Malaysian isolate) and $18252 \mathrm{bp}$ (bangladesh isolate) Genome has six transcriptional unit that has six structural proteins. They are nucleocapsid $(\mathrm{N})$, phosphoprotein $(\mathrm{P})$, matrix protein $(\mathrm{M})$, fusion protein $(\mathrm{F})$, glycoprotein $(\mathrm{G})$ and polymerase (L) Protein associated with genome: large (L) protein, phospoprotein (P) Viral proteins: fusion protein $(\mathrm{F})$ and attachment glycoprotein protein $(G)$ Phosphoprotein $(P)$ : it role as a polymerase cofactor, enhancing polymerase processivity and allowing the encapsidation of the newly synthesized viral genomes and antigenomes. Phosphorotein of Nipah virus has an additional role in immunosuppression: blocking interferon signaling by binding host STAT-1.

It's replication requires a constant supply of unassembled nucleoprotein (NO) in complex with its viral chaperone, the phosphoprotein. Host attachment is achieved by the viral $G$ protein that binds to the host cell surface receptors ephrin B2 or B3 $(8,9)$. Next, the cellular and viral membranes fuse and the capsid disassembles to deliver the viral genome into the cell. Once in the cytoplasm, the viral messenger and genomic RNAs aresynthesized and translated to generate viral proteins. Successful infection requires evasion of the interferon (IFN)- $\alpha / \beta$ response (a key component of the innate immune response to virus infection). Four Nipah-encoded proteins $(\mathrm{P}, \mathrm{V}, \mathrm{W}$, and $\mathrm{C}$, all encoded by the $P$ gene) participate in overcoming the innate immune response [9].

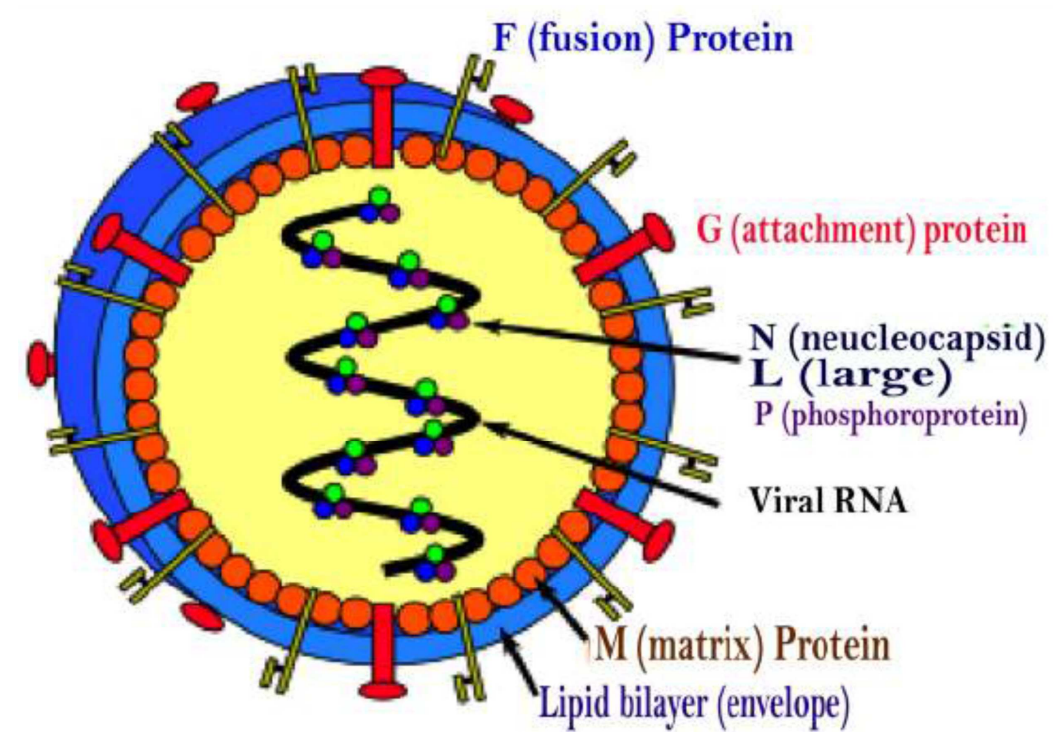

Figure 1. Structure of Nipah Virus.

Nipah virus (NiV) is a RNA virus belongs to family Paramyxoviradae and genus Henipavirus.

Size: $40-600 \mathrm{~nm}$

Shape: pleuromorphic

Envelope: present

\section{Mode of Transmission}

It was discovered that the main carrier of the virus are four species offruit bats. The virus was found in the urine and saliva of infected flying foxes (bats) and pigsconsuming food contaminated by these secretions can be infected. This occurs especially when the pig farms are located close to fruit orchards or fruit trees that attracted flying foxes. It can be transmitted to humans from animals such as bats, pigs etc via intake of fruits bitten by bats or contaminated by the sick animals urine [10]. Nipah virus also spread to Pigs, cows, horses, cats, sheep, goat etc through bats. It can also spread 
from humans to humans through body fluids. Transmission of infection occurs via respiratory droplets, contact with both the body fluids andtissues of a sick animals. Niv virus is highly contagious among pigs and is spread by coughing. As per some epidemiological study reports bats excrete these virus when they are in stress and when they are pregnant. Incidents of human-to-human transmission have alsobeen reported, with these being the major route of infection for the Bangladeshi strains.

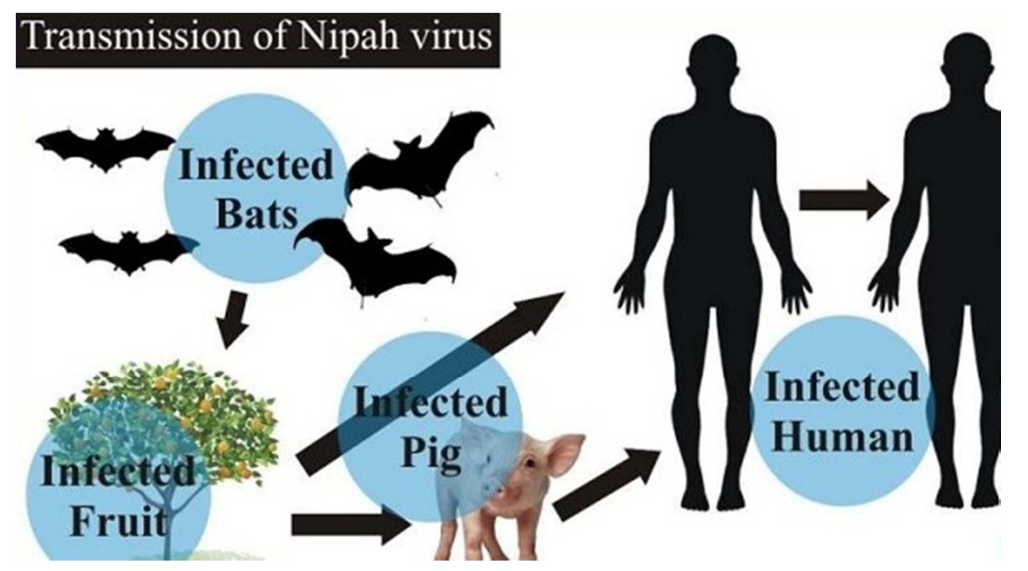

Figure 2. Mode of transmission of Nipah Virus.

\section{Incubation Period and Pathogenesis}

The incubation period of this virus is from 4 to 14 days. However, an incubation period as long as 45 days has been reported. Infected pigs may develops symptoms such as acute respiratory and neurological illness. Nipah virus are belived to infect respiratory tract epithelial tissue resulting is shedding of epithelial lining along with nasopharyngeal secretion. Soon Patients develops symptomatic respiratory infection, which is characteristic feature of early stage of infection. Followed by, During late stage, virus spread to lungs endothelium resulting in endothelial syncytium and mural necrosis [11]. Nipah virus can then enter the bloodstream and disseminate throughout the host in either free form or by binding host leukocytes. (Nipah virus has been shown to bind to CD3+ leukocytes without entry or replication of the virus). Other target organ of Nipah virus the brain, spleen and kidneys. Entry of Nipah virus into the CNS is thought to occur through two distinct pathways: anterogradely via the olfactory nerve and/or via the hematogenous route through the choroid plexus and cerebral blood vessels. Infection of the CNS in humans is characterized by vasculitis, thrombosis, parenchymal necrosis, and presence of viral inclusion bodies. Mostly at the end victims die with CNS involvement such as encephalitis.

\section{Signs and Symptoms}

Nipah virus infections in humans has a range of effects from asymptomatic infection toacute respiratory distress syndrome and fatal encephalitis.

Infected people initially shows influenza like symptoms of fever, headaches, myalgia, vomiting and sorethroat.

Followed by, the patients show dizziness, drowsiness, altered consciousness and neurologic signs such as encephalitis, personality changes and brain stem dysfunction.

Some patients can also experience atypical pneumonia and severe respiratory problems including acute respiratory distress. In more severe cases patient suffer from encephalitis and seizure and which will progress to coma within 24 to 48 hours [12].

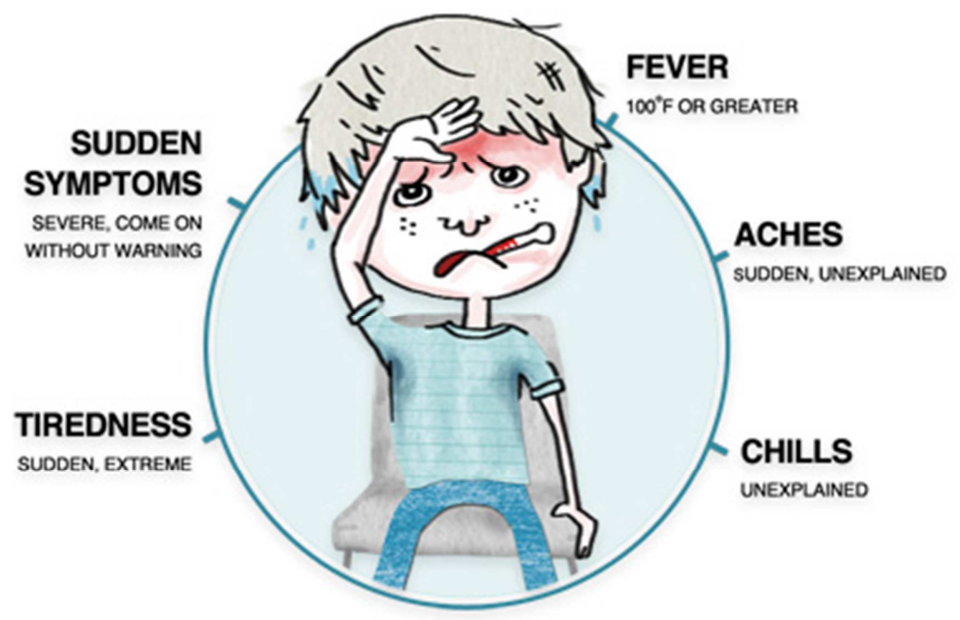

Figure 3. Clinical features in children. 


\section{Diagnostic Measures}

Niv infection may be asymptomatic at first that often makes it difficult to diagnose the disease in the initial stage [13]. Clinical presentation of the patient also helpful for detecting the infection. Some of the main tests including

Real time polymerase chain reaction (RT-PCR) from body fluids

Enzyme-linked immunosorbent assay (ELISA) for antibody detection

Polymerase chain reaction (PCR) assay and

Virus isolation by cell culture also helpful for identifying the infective organism. Different diagnostic measures use at various stages of illness

\section{Treatment \& Preventive Measures of NIV Infection}

There are currently no drugs or vaccines are available which is specific to Npiah virus infection. Hence the the treatment is limited to supportive care. Admit the patient in the intensive care unit for 24 hours monitoring after the diagnosis is made confirmed. Management of fever and the other neurological symptoms are the prime concern in the intensive care unit. Ribavirin may alleviate the symptoms of nausea, vomiting and convulsions. Keep the patient hydrated. Moreover as there are no options for treatment of disease, the prime focus should be given to preventive measures.

1. Avoidance of contaminated fruits which is bitten by infected animals.

2. Restrict or isolate the movement of infected people or animals

3. Prevent farm animals from eating fruit contaminated by bats.

4. Avoiding consumption of contaminated date palm sap. Freshly collected date palm juice should be boiled and fruits should be thoroughly washed and peeled before eating.

5. Wash the utensils, if suspected the contamination, with $8.5 \mathrm{Ph}$ alkaline solution as it has the power of destroying cell wall of Nipah virus.

6. Similarly wash the vegetables and fruits with water after adding some baking soda/ sodium bicarbonate into that water as it can change the nature of that water to alkaline and destroy the virus. Keep the eatables for one minute in that water to destroy the virus.

7. Routine and thorough cleaning and disinfection of pig farms with appropriate detergents.

8. In case, an outbreak is suspected, the premises of animals should be quarantined immediately.

9. Culling on infected animals may be necessary to reduce the risk of transmission to people. This has to be carried out with close supervision of burial or incineration of carcasses.

10. In health care settings, health care team members has to wear all the PPE to avoid the contact with body fluids of patients.

11. Isolate the patient and use disposable materials for the patient. Use 2\% gluteraldehyde solution for autoclaving the instruments used by the patient.

12. Consult a veterinary physician if the domestic animals shows unusual weakness or runny nose

13. Regular hand washing, for a minimum of 20 seconds, with alcohol based savlon solution is recommended after visiting and caring the patient.

14. Close unprotected physical contact with Nipah virus infected people should be avoided.

15.In all health care setting, standard infection control precautions has to be maintained while treating Niv infected patients.

16. Wear N95 mask while taking samples from patient for investigations [14].

\section{Prognosis}

Nipah is fatal in a larger number of case and has a fatality rate between $40-75 \%$ according to WHO. As per the research report from Bangladesh, it had a fatality rate of $54 \%$, ie 315 deaths occurred out of the 582 cases studied. Most people who survive acute encephalitis make a full recovery, but long term neurologic conditions have been reported in survivors. Approximately $20 \%$ of patients are left with residual neurological consequences such as seizure disorder and personality changes. A small number of people who recover subsequently relapse or develop delayed onset encephalitis.

\section{Conclusion}

Although Nipah viral infection is there in the WHO R\&D list, it is sorry to mention that the awareness among the common people regarding this illness is very less. Hence improving the awareness regarding Nipah virus and prevention of cross infection of this disease is very much helpful for preventing the occurrence of this illness. As preventive measures is the only measure to avoid this disease, the knowledge about the same will be very much helpful for saving the life of human beings and to reduce the mortality rate.

\section{References}

[1] World health organization. 2018 may 26. Surveillance and outbreak alert. Nipah virus outbreaks in the south east Asia region. www.who.int/csr/disease/nipah/en/.

[2] Amina Zafar. CBC news. 2018 may 28. Nipah virus outbreak in india 'definitely a concern', Canadian scientist says.www.cbc.ca/news/health/nipah-virus-faq-1.4677079.

[3] S. P. Luby. The pandemic potential of Nipah Virus. Antiviral Research. Vol. 100, October 2013, p. 38.doi:10.1016/j.antiviral. 2013. 07. 001. 
[4] S. P. Lubystal. Recurrent zoonotic transmission of Nipah Virus into humans. Bangladesh. 2001-2007. Emerging infectious disease, vol. 15. August 2009, p. 1229. http://dx.doi.org/10.3201/eid1508.081237.

[5] O. A. Negrete et al. EphrinB2 is the entry receptor for Nipah virus, an emergent deadly paramyxovirus. Nature. Vol. 436, July 6, 2005, P. 401-405.

[6] Maanvi singh. May252018. Here's what we know about the deadly Nipah Virus. http://www.sciencenews.org/article/hereis-what-we-know-about-deadly-nipahvirus.

[7] D. D. Kulkarnietal. Nipah virus infection: current scenario. Indian J Virol. 2013 Dec; 24 (3): 398-408.

[8] Arankalle V et al. Genomic characterization of Nipah virus, West Bengal, India. Emerg Infect Dis. 2011; 17:907-909. doi: 10.3201/eid1705.100968.

[9] Times now digital. may 23.2018. Nipah virus outbreak in kerala: 10 shocking facts you must know about this deadly disease.www.timesnownews.com > Health.
[10] Neethu C. Sharma. May 23 2018. 12. What is Nipah virus and how is it transmitted?https://www.livemint.com > Science , Health.

[11] Neethu C. Sharma. May 22 2018. Third outbreak of Nipah Virus in India since 2001. What are the reasons? https://www.livemint.com > Science > Health.

[12] Times Now Digital. may 232018. Nipa virus outbreak: Kerala issues health advisory to people travelling to the state. www.timesnownews.com > Health.

[13] BS Web Team. may 24, 2018. Nipah virus outbreak in India: Know about its symptoms, treatment, New delhi: www.business-standard.com/.../nipah-virus-in-kerala-nipahsymptoms-treatment-severe.

[14] BS Web Team. may 25, 2018. Nipah Virus: Symptoms, precautions, facts, cure, New delhi.

[15] "Nipah virus outbreaks in the WHO South-East Asia Region". South-East Asia Regional Office. WHO. Retrieved 23 May 2018. 